\title{
ACERCA DEL LIBRO DE JESÚS CONTRERAS UGARTE: REALIDAD, PODER, VALORES Y DERECHOS HUMANOS: EL PODER DOMINANTE EN MAX WEBER
}

\section{ABOUT THE BOOK OF JESUS CONTRERAS UGARTE: REALITY, POWER, VALUES AND HUMAN RIGHTS: THE DOMINANT POWER IN MAX WEBER}

Eduardo Gago Fernández-Rubalcaba ${ }^{1}$ Máster en Derecho Internacional Universidad Complutense de Madrid pedrogago@trs.ucm.es España, Madrid

\section{SUMARIO}

- Opinión sobre la introducción del libro

- Opinión sobre la investigación

- Conclusión

\section{RESUMEN}

El opinante expone y analiza el pensamiento del autor del libro Realidad, poder, valores $y$ Derechos Humanos: El poder dominante en Max Weber.

\begin{abstract}
The speaker exposes and analyzes the author's thought of the book Reality, power, values and Human Rights: The dominant power in Max Weber.
\end{abstract}

\section{PALABRAS CLAVES}

Realidad; Poder; Valores; Derechos Humanos.

\section{KEYWORDS}

Reality; Power, Values; Human rights.

\section{OPINIÓN SOBRE LA INTRODUCCIÓN DEL LIBRO}

En la introducción del trabajo del Doctor Jesús Contreras, Realidad, poder, valores y derechos humanos. El poder dominante en Max Weber, parece estar motivado por una inquietud provocada por los cambios que se han producido en nuestros días. Es probable que sea el situacionismo actual lo que ha movido al autor a estudiar al sociólogo alemán, por lo que no es una cuestión banal servirse de un autor para penetrar en la realidad. Desgraciadamente en el área de conocimiento de la Teoría y Filosofía del Derecho se suele dar en exceso la especulación imaginaria. Lo que Weber llama la irracionalidad que procede del sentimiento y cuyo rasgo más destacable es la irracionalidad axiológica. También sucede al revés, que muchos juristas dedicados a la práctica jurídica no estiman más que el derecho positivo. En el trabajo que nos ocupa, Jesús Contreras parte de unas exigencias intelectuales para responder a unas necesidades reales, motivo por el que se decide estudiar las "nuevas hegemonías de dominación". Se estima a priori que podría fundamentarse suficientemente la existencia de unos poderes que podrían poseer más fuerza que las instituciones democráticas, aunque estas sean la expresión de la voluntad popular.

\footnotetext{
1 Graduado en Derecho, Máster Profesional en Práctica de la Abogacía. Máster en Derecho Internacional. Becario con contrato PreDoctoral de personal investigador en formación. Universidad Complutense de Madrid - Banco Santander.
} 
Al escoger el estudio del poder en sus diferentes posibilidades y derivaciones, el trabajo nos parece que se inserta más en un estudio de pensamiento político, aunque esté muy marcada la relación con lo jurídico. En sustancia, el libro trata más bien de los diferentes modos que adopta el poder político.

En cuanto al origen del estudio y del rasgo inicial planteado por el doctor Contreras lo que se plantea es que "el poder que domina al Estado desde la sombra de sus manipulados" (página 10). A partir de esta hipótesis, logrará hacer un riguroso análisis sobre el poder de dominación en Max Weber, demostrando, paralelamente, que su teoría servirá para penetrar con suficiente hondura en las estructuras de poder actuales, delimitando, con notable precisión conceptual a lo largo del trabajo, las llamadas regularidades fácticas, al ser los modos de fijar el orden dependiendo de su importancia.

El concienzudo trabajo sigue organizadamente el desarrollo weberiano, no siempre fácil de transmitir. Aunque Max Weber no pretenda ser filósofo, ni su intención fuera la de abarcar todas las áreas de conocimiento, sin embargo, ha sido capaz de crear un cierto sistema de sociología dentro de su dispersión metodológica, sin que quepa hablar de leyes generales determinantes del porvenir, que sólo por los límites de la disciplina tendrá que circunscribirse al ámbito estricto de estudio, si bien hará continuas modificaciones como corresponde el carácter científico de su labor, en línea con la ratio cognoscendi. Y, por supuesto, porque el ámbito totalitario al que propende la filosofía ya entonces era imposible de conseguir.

Lo evidente es que Weber establece una relación entre historia, de la cual surgieron los prototipos, los modelos, las desviaciones, los caracteres, las interpretaciones, etc. y el presente. Él ahora le exige a Max Weber una ciencia de la realidad social que le llevará a postular unos modelos que son producto del situacionismo, tanto en la política como en el derecho, si bien le impedirá cerrar una axiología aplicable a todo tiempo y lugar y defender un relativismo de los valores. Precisamente la axiología relativista es clave para entender la realidad y el poder, diferenciando el juicio de valor (Werturteil) y la relación con los valores (Wertbeziehung), sea la materia histórica o sociológica respecto a los valores -el ejercicio del hombre político-, que son personales -la actividad intelectual del sabio-.

En el título del trabajo ya se vislumbra la importancia del significado realidad, siendo el motivo por el que se indagará sobre el presente a partir de las concepciones weberianas. Así pues, no se intentará analizar intelectualmente las ideas de Weber sobre el poder, la racionalidad y la burocracia, sino averiguar si es posible utilizarlas como instrumentos efectivos para conocer los aspectos más determinantes de la realidad, con las limitaciones que parten de la diferencia, siempre excesiva, entre concepto y realidad, en el sentido que le da Weber.

Al escoger los instrumentos necesarios para comprender-verstehen- tanto lo que acontece, como lo que está instituido en un proceso más o menos determinable de la conducta y el ejercicio del poder, el autor ha partido de una lógica irreprochable: adaptar las ideas weberianas fundamentales. Cualquiera que haya trabajado estos temas sabe que exponer las ideas de Max Weber no es tarea fácil, en mayor medida, al ser tan numerosos los estudios que se han hecho sobre su pensamiento, cuando se ha complicado el intento de estudiarlo con la mayor objetividad. Problema que ha sucedido varias veces con los grandes pensadores. Sin embargo, Jesús Contreras ha acertado plenamente en la elección de los temas, tanto por ser muy atractivos, ya que el poder y los valores ocupan una parte fundamental de la vida humana, y porque ha conseguido dar a la teoría weberiana la utilidad necesaria para entender aspectos del presente mediante un complicado proceso de aprehensión y adaptación. Hay que ser consciente de que, si un autor estudiado no logra actualizarse, sin perder su auténtico sentido, solo se hará una historia fosilizada del pensamiento. $O$ se prefiere una simple referencia más o menos compleja al pasado.

\section{OPINIÓN SOBRE LA INVESTIGACIÓN}

En la investigación, Jesús Contreras consigue dos objetivos que harán de su lectura una necesidad para el intérprete del presente: 1. Lograr exponer el pensamiento weberiano con una estructura impecable, basada en dividir en múltiples apartados, permitiendo al lector entender muy bien al sociólogo alemán. 2. La precisión con la que se expone el pensamiento weberiano podría ser un diccionario de términos weberianos muy útil para el que quiere 
derechos humanos: el poder dominante en max weber

About the book of jesus contreras ugarte: reality, power, values

and human rights: the dominant power in max weber

afrontar su estudio, por lo que es aconsejable su lectura para quien esté interesado en su pensamiento y para quienes se han servido de sus concepciones. Es preciso repetir que al estudiar a Max Weber no se quiere hacer una recopilación de su amplio muestrario de sus conceptos e ideas, sino para tenerlos como una base sólida de penetración en la realidad.

De un modo más específico, el trabajo se centrará en la relación, imprescindible en todo conjunto humano, entre la acción social y la dominación, esto es, entre dominantes y dominados, del que surgirá las correspondientes relaciones siempre favorables a estos últimos, pues casi siempre quedará a merced de la utilización de la fuerza o de la coacción psíquica por parte de los dominantes. En esta relación tendrá una importancia vital el Derecho, encargándose el autor de exponer la postura weberiana del ser y del deber ser a partir de su origen kantiano.

Al hilo de este asunto, como un pilar en el que se asientan las relaciones de dominación, se encuentra el mantenimiento del orden, "como conjunto de regularidades fácticas expresadas en acciones sociales" (Página 272). Esto es, explicar (Erklären) las regularidades de las conductas de los hombres. El orden que se impone por la dominación queda establecido en una tipología que responde a las diversas formas de su legitimación. Con estas convergencias el Doctor Contreras irá exponiendo paso a paso, desde el orden jurídico y sociológico, a la dominación como poder que se refleja en un campo muy amplio que abarcará el uso, la costumbre, las convenciones, la legitimación, la legalidad, y los menos legítimos, caso de la burocracia, para terminar en el racionalismo, que se llevará a cabo en diferentes contextos, siempre en relación con los diversos elementos de la Sociedad y el Estado. Hay una mención especial a la economía capitalista, estudiada en sus dos obras capitales: Wirtschaft und Gesellschaft. Grundriss der Verstehenden Soziologie, (Economía y Sociedad. Esbozo de sociología comprensiva), aparecida después de su muerte (1923), y Die protestantische Ethik und der Geist des Kapitalismus y Die protestantischen Sekten und der Geist des Kapitalismus, (1904 y 1905). Traducción española: La ética protestante y el espíritu del capitalismo.

Atención especial merece el capítulo III, uno de los más llamativos del libro, al quedar muy concretado, por un lado, la concepción de la política de poder (Machtpolitik) partiendo de la idea de Darwin y Nietzsche sobre la lucha entre las clases y los individuos por conquistar el poder (Macht), y, por otra, mantenerse en el poder con dominio (Herrschaft), que no posee un sentido negativo, sino que se logra mediante la obediencia voluntaria. Se entiende que la idea de poderío es diferente al término Autorität, que designa más bien la naturaleza propia de una institución, o la personalidad del que lo ostenta. Precisamente será aquí donde quepa entender todas las relaciones sociales, ya que, en efecto, desde la perspectiva política las acciones forman parte de una ética de la responsabilidad (Verantwortungsethik) y una ética de la convicción (Gerinnungsethik). La primera tiene que adoptarla el político, el hombre de Estado, que busca la eficacia, mientras que la segunda se basa en el sentimiento, en atender a la relación mediosfines y a las posibles consecuencias. Ante esta situación, y con la importancia que se da al sistema capitalista, que Weber denomina "organización social del trabajo libre", y a la burocracia, que podía pertenecer a una organización anónima de la que la persona quedaba sometida, se podrá entender la pregunta de Jesús Contreras, “¿Qué hacer con lo que se hace de nosotros?” (Página 278).

Puesto que se parte del principio fundamental de la dignidad humana, no cabe más remedio que dar un salto hasta los derechos humanos como regidores universales de la acción social. Si bien irá acompañado de un proceso en el que es necesario regularizar racionalmente y en tanto se aplique "la Teoría de la Empatía del Reconocimiento" (Página 281).

Respecto a la división llevado a cabo por Jesús Contreras Ugarte se justifica por la intención de estructurar el tema, a fin de aclarar, por una parte, la concepción de Max Weber sobre los conceptos e ideas, y, por otra, para llegar al fin propuesto, que es dejar constancia de que en la realidad hay un poder dominante que se encuentra en relación con la legitimidad, la legalidad, y los diferentes tipos de dominio, en los, que desde el objetivo, se hace una revisión, además de asentarse en las ideas de racionalidad en sus diferentes relaciones. Ahora bien, los conceptos derivan de su composición a lo largo del tiempo, es decir, que son históricos, por lo que nos encontraremos con una detallada explicación de las causas que han formado las 
estructuras, no sólo de dominación, sino de racionalidad, por haber sido imprescindibles para mantener la cohesión del cuerpo social. Sería el caso de la costumbre, la convención y el Derecho, que nuestro autor denomina "las Regularidades Fácticas del Comportamiento del orden social". Quizá el siguiente paso probablemente será ejemplificarlo en el muestrario histórico de casos, en tanto supone la adaptación del concepto a la realidad.

En el libro está bien examinadas las ideas que se establecen en relación con la propia constitución del poder, de la dominación, e incluso del poderío. El planteamiento sobre esta cuestión no sólo busca adjetivar la estructura del poder y de la dominación, sino establecer los nexos de unión a partir de las relaciones sociales, por lo general las de mayor influencia. El propósito consiste en hacer ver la necesaria comunicación entre el poder o la dominación, y las necesidades sociales en sus diferentes grados y formas, a partir de las cuales se reclamará una obediencia voluntaria o forzada.

En el trabajo objeto de esta reseña el autor llegará a la conclusión de que son tres los rasgos en los que se asienta el poder dominante: la racionalidad, su origen histórico (Página 211) y la dominación "burocrática" (especie de dominación racional o legal), "la más pura de las formas de dominación legal” (página 182). La racionalización y la burocratización van en paralelo y, según Max Weber, así seguirán en el futuro, porque es una relación causal, si bien se podría explicar con determinación la condición humana concreta en cualquiera de las facetas en que se desarrolla la vida humana, aunque de ello no se infiere que den lugar a un tipo de pensamiento o a un sistema político. Esta degeneración de la administración contemplada en el estudio, ha surgido por su tendencia a "sobrepasar su función administrativa" (página 193), por lo que podría decirse que es un producto de la degradación del Estado de Derecho. Es decir, que si la administración es imprescindible tanto para el Estado como para la sociedad, la burocracia es un poder constituido por sí mismo y para sí mismo, por lo que tendrá unos intereses que no son los de la sociedad. Debiéndose añadir para entender su consecución que su aparición también es obra de la incapacidad de la sociedad para controlar cualquier régimen, incluido los diferentes tipos de democracia. Sin olvidar, como bien ha quedado estudiada en el trabajo (Páginas 238 y ss.), la relación con el racionalismo. Es decir, la racionalidad va de la mano con la burocracia, que es una forma que adopta modernamente el poder público.

Más que desde una sociología política, el estudio sobre el poder y la dominación, se hará a partir de la teoría política weberiana, al objeto de establecer una asociación muy clara con la perspectiva jurídica, que, por lo general, estará subordinada al propio concepto de poder, ya que "la legitimidad y la legalidad son atributos del poder. La legitimidad vendría a ser el requisito de la titularidad, y la legalidad el requisito del ejercicio del poder" (página 158). Idea que entendemos que también habrá que desarrollar a partir de la historia y del presente, pues "la creencia en la legitimidad del poder ha cedido el paso a la idea de legalidad" (página 159).

Teniendo presente el neokantianismo cultural, muy en la línea de la intención de Max Weber de hacer una ciencia sociológica del Derecho, el Doctor Contreras plantea la relación entre legalidad y legitimidad, dentro de lo que Max Weber llama la mentalidad axiológica. Es importante destacar esta relación, porque a su vez su origen se halla en otra relación, la que procede de lo político: el mando y obediencia. Entre ellas destacará el aparato administrativo que habrá de tener la dosis suficiente de legitimidad, y, por supuesto, de Autoridad, dejando bien claro que no es simple poder, pues la que legitima es la potestas, o más bien que la legitimidad es la que crea la autoridad, si bien no se establece de una sola forma debido a que hay varios tipos de "dominación legítima" (páginas 168 y ss).

Aconsejamos a cualquier lector que haya pasado por alto alguna idea destacable o que prefiera ir ajustando su lectura a un proceso de construcción podrá consultar a partir de la página 262 hasta la página 267, por haber hecho el autor una síntesis muy lograda sobre la racionalización, entendida como coordinación y organización de las múltiples actividades humanas, con el fin de dominar la exterioridad, y el poder dominante sin perderse el rigor necesario. Incluso quien se interese primero sobre cuáles son las ideas principales desarrolladas, también podrá recurrir a este resultado para luego leer en el libro con mayor esparcimiento. Se nota que el autor ha cuidado 
derechos humanos: el poder dominante en max weber

About the book of jesus contreras ugarte: reality, power, values

and human rights: the dominant power in max weber

que el trabajo quede suficientemente claro para el interesado en estudiar a Max Weber, con un sentido casi matemático de la estructura y de la organización los aspectos claves que permiten entender, sin error, al sociólogo alemán.

Otro de los logros del trabajo del Doctor Contreras ha consistido en lograr ceñirse a los temas examinados, lo que metodológicamente no siempre es fácil, ya que requiere además de aprehender bien la obra weberiana, saber insertarle en su época para lograr el objetivo de adaptarlo al presente, recurriendo cuando sea preciso a varias disciplinas indispensables que afronten de manera directa o indirecta el poder. La dificultad aumenta al conocer que la materia que analiza es bastante polémica, tanto o más que en tiempos del gran pensador teutón.

En efecto, analizarel poder exige principalmente hacerlo desde la política, a partir de la cual se invaden todas las actividades humanas. Un rasgo destacable del trabajo es la intención del autor de no elegir arbitrariamente las ideas weberianas para exponerlas con la única pretensión de afirmar un contenido doctrinal. $\mathrm{Su}$ intención parece ser la de traspasar al lector de manera objetiva los resultados de la utilización de los instrumentos para aplicarlos a la realidad en que se encuentre. Después de todo el Doctor Contreras ha conseguido asimilar, sin prejuicios, los contenidos escogidos de la obra weberiana y aprovecharlos para adaptarlos al presente. De modo que valga lo uno y lo otro. Con ello se demuestra que algunas concepciones weberianas todavía sirven para interpretar la realidad. Teniendo presente que para $M$. Weber parte de la concepción protestante del desencantamiento del mundo, y que el hombre ya no practica las virtudes. Su perspectiva es claramente alemana, desgarrado por las contradicciones internas y su percepción del poder basada en la lucha entre los hombres, con un profundo pesimismo sobre la política, aunque sea la base de la extensión de la cultura, y que muchas veces el prestigio proviene de la victoria en la guerra, por lo que hay un vínculo entre el poder, siempre diabólico, otra vez el protestantismo sea el que extienda la cultura, aunque no la cree. De modo que el poder y la cultura están unidos. $\mathrm{O}$, si se prefiere, el pueblo de cultura (Kulturvolk) estaría unido a la política de poder (Machtpolitik).

Si Jesús Contreras hubiera querido hacer un estudio de la obra de un autor sin más pretensiones, probablemente habría acudido a cualquier pensador menos exigente que Max Weber para elevarse con objetividad sobre las deformaciones de lo aparente. El objetivo ha sido mucho más ambicioso. Ya que la intención ha sido exponer una parte fundamental de su obra en su verdadera concepción, así como recoger lo que pueda ser útil para enjuiciar la realidad sin criterios o juicios arbitrarios.

Por este motivo el lector agradecerá la preocupación por objetivar todos los conceptos weberianos, evitando las interpretaciones innecesarias que suelen oscurecer o relativizar las ideas del sociólogo alemán. De ahí la voluntad de hacer una ciencia de la realidad especificada en la racionalidad del poder $y$ en sus derivaciones, esto es, ciencia de lo que existe, siempre inacabada, por lo que nunca puede alcanzar su fin. De ahí que necesite hacer ciencia con la ciencia como un proceso indetenible del conocimiento. Lo que no implica que la ciencia pueda exponer el futuro y decir cómo deben vivir las personas.

Otra cuestión destacable. En el trabajo se distinguirá bien lo que es una actividad constante en las sociedades humanas, de lo cambiante, sobre todo en las sociedades modernas, en la que ha afectado, como es lógico, las decisiones humanas en el ejercicio del poder y en las mentalidades colectivas. Indiscutiblemente siempre hay una permanencia del fenómeno del poder, en consideración o correspondencia con lo político y la política. De este modo afectará a todas las relaciones específicas de las instituciones, pero también de las relaciones sociales, por lo que el trabajo no se ha conformado con exponer lo singular y lo convencional, ya que el propósito es captar con la máxima precisión las diferentes conformaciones weberianas del poder, transformando a partir de los rasgos epistemológicos y con una metodología adaptativa que relaciona la concepción con la realidad social como instrumento de precisión de su obra. El Doctor Contreras tiene presente las ambigüedades de la obra de weber como estudioso de la Machtpolitik, por lo que no siempre su teoría es posible adaptarla al presente. Pero es indudable que la política de poder caracteriza la política internacional, de modo que la lucha por el poder es el rasgo más singular de la política. En caso contrario se estaría haciendo impolítica. 


\section{CONCLUSIÓN}

En suma, en la reflexión de Jesús Contreras el problema del poder se enmarca dentro de las nociones jurídico-éticas y en la practicidad política. La idea de legalidad tan prodigada en el trabajo, justificadamente en los momentos actuales, aunque esté muy dirigida por lo político, no abre una vía a un procedimiento que pueda ser adaptado a las necesidades actuales del poder. La legalidad no supone resolver los conflictos, pero da la autoridad para afrontarlos con mayores garantías, sin que haya que suponer que deba ser un instrumento de la actividad política.

\section{FUENTES DE INFORMACIÓN}

\section{Fuente bibliográfica}

Contreras Ugarte, Jesús (2018). Realidad, poder, valores y derechos humanos: $E l$ poder dominante en Max Weber. $1^{\circ}$ edición. Madrid, España: Servicio de Publicaciones de la Facultad de Derecho de la Universidad Complutense de Madrid. 